\title{
Hyperbaric oxygen: a novel modality to ameliorate experimental colitis
}

\author{
D Rachmilewitz, F Karmeli, E Okon, I Rubenstein, O S Better
}

\begin{abstract}
Background-Hyperbaric oxygen (HBO) has been suggested to be beneficial in inflammatory bowel disease but the mechanisms responsible for its therapeutic effects have not been elucidated.

Aim-To assess the effect of HBO treatment on colonic damage in two models of experimental colitis, and to examine whether this effect is mediated by modulation of NO synthesis.

Methods-Colitis was induced by either flushing the colon with $2 \mathrm{ml} \mathrm{5 \%}$ acetic acid or intracolonic administration of $30 \mathrm{mg}$ trinitrobenzenesulphonic acid (TNB) dissolved in $0.25 \mathrm{ml} 50 \%$ ethanol. Rats were exposed to $\mathrm{HBO}(100 \%$ oxygen at 2.4 atmosphere absolute) for one hour twice on the day of colitis induction and once daily thereafter. Control rats were treated only with acetic acid or TNB. Rats were killed 24 hours after acetic acid administration or one and seven days after TNB treatment. The colon was isolated, washed, and weighed, the lesion area was measured, and mucosal scrapings were processed for determination of myeloperoxidase (MPO) and NO synthase (NOS) activities, prostaglandin $\mathrm{E}_{2}\left(\mathrm{PGE}_{2}\right)$ and leukotriene $\mathrm{B}_{4}\left(\mathrm{LTB}_{4}\right)$ generation.

Results-In control rats exposed for seven days to HBO, colonic NOS activity was significantly decreased by $61 \%$, compared with its activity in untreated rats (2.93 (0.17) $\mathrm{nmol} / \mathrm{g} / \mathrm{min})$. HBO significantly reduced by 51 and $62 \%$ the extent of injury induced by acetic acid and TNB respectively. The protection provided by HBO was accompanied by a significant decrease in colonic weight, $\mathbf{P G E}_{2}$ generation, MPO, and NOS activities. In acetic acid colitis, $\mathbf{L T B}_{4}$ generation was also significantly decreased.
\end{abstract}

Conclusions-(1) HBO effectively decreases colitis induced by acetic acid and TNB. (2) The decreased NOS activity induced by $\mathrm{HBO}$ suggests that reduction in NO generation may be among the mechanisms responsible for the antiinflammatory effect of HBO. (3) $\mathrm{HBO}$ may be considered in the treatment of patients with refractory inflammatory bowel disease.

(Gut 1998;43:512-518)

Keywords: hyperbaric oxygen; acetic acid colitis; trinitrobenzenesulphonic acid colitis; inflammatory bowel disease
Hyperbaric oxygen (HBO) has been used as a safe and effective treatment in various clinical and experimental conditions ${ }^{1}$; it has been shown to be effective in air embolism decompression sickness and carbon monoxide poisoning. Its physiological effects on plasma oxygen content supported the use of $\mathrm{HBO}$ in patients with severe anaemia who cannot be transfused with blood and, despite less scientific support, favourable reports in various other indications are encouraging. Inhibition of neutrophil adherence and prevention of postmuscle crush vasodilation ${ }^{2}$ are among the other favourable effects ascribed to HBO. In the gut, $\mathrm{HBO}$ has been reported to ameliorate experimental small intestine ischaemia-reperfusion injury $^{3}$ and to be of benefit in patients with severe perianal Crohn's disease. ${ }^{45}$

The inflamed intestinal and colonic mucosa in inflammatory bowel disease (IBD) is infiltrated by neutrophils, macrophages, and lymphocytes. In the inflamed intestinal mucosa of patients with IBD, the generation of eicosanoids and leukotrienes by epithelial and inflammatory cells has been shown to be enhanced $^{6}$ and has been suggested to have a role in the pathogenesis of the inflammatory response. In addition to oxygen free radicals generated by stimulated polymorphonuclear cells, eosinophils, xanthine oxidase, colonic bacteria, and epithelial lipoxygenase, all of which are present in the inflamed bowel of patients with IBD, intestinal NO generation is also increased in models of experimental colitis and in patients with IBD. ${ }^{7} \mathrm{NO}$ contributes to tissue injury by reacting with superoxide; NO and superoxide are simultaneously synthesised by activated macrophages and inflammatory neutrophils. The product of this reaction is peroxynitrite, a powerful oxidant shown by us to induce severe colonic inflammation. ${ }^{8}$ There is no definite indication as to the relative contribution of each of the mediators to the inflammatory cascade, but it is conceivable that free radicals, NO, and superoxide are the final agents responsible for the infliction of tissue damage. The amelioration of experimental colitis induced by $N^{\mathrm{G}}$-nitro-L-arginine methyl ester (L-NAME), ${ }^{9}$ an inhibitor of NO synthase (NOS), and by nitroxides,${ }^{10}$ potent scavengers of oxygen free radicals, indicates the pivotal role of free radicals in the pathogenesis of tissue damage in general and colonic injury in particular.

In view of the favourable response to $\mathrm{HBO}$ treatment of perianal Crohn's disease, the purpose of this study was to assess the effect of HBO treatment on the extent of tissue damage in two models of experimental colitis. Moreover,
Accepted for publication 23 March 1998 
since hyperbaric oxygenation has been shown to reduce transcription of the NOS gene and peroxynitrite synthesis of mouse peritoneal macrophages, ${ }^{11}$ we tested its effects on the inflammatory mediators and NOS activity in experimental colitis induced by acetic acid and trinitrobenzenesulphonic acid (TNB).

\section{Materials and Methods}

L-Arginine, L-citrulline, L-NAME, NADPH, dithiothreitol, phenylmethanesulphonyl fluoride, EDTA, and EGTA were purchased from Sigma Chemical Co. (St Louis, Missouri, USA), Dowex AG50W-X8 (sodium form, 100-200 mesh) and Tris base (electrophoresis grade) from Bio-Rad Laboratories (Richmond, California, USA), and aquasol-2 from DuPont/ NEN Research Products (Bad Hamburg, Germany).

ANIMALS

Male Sprague-Dawley rats, weighing 200-250 $\mathrm{g}$ and fed ad libitum, were used in all studies.

ACETIC ACID INDUCED COLITIS

Acetic acid colitis was induced under light anaesthesia. A midline abdominal incision was made and the colon isolated; $2 \mathrm{ml} \mathrm{5 \%}$ acetic acid was injected into the lumen of the colon at its proximal part through a 25 gauge needle followed by $3 \mathrm{ml}$ air, which cleared most of the acetic acid from the colon. The midline incision was closed. After 24 hours the rats were killed and their colons removed.

\section{TNB INDUCED COLITIS}

Colitis was induced under light anaesthesia by a single intracolonic administration of $0.25 \mathrm{ml}$ $50 \%$ ethanol containing $30 \mathrm{mg}$ TNB. The solution was introduced via a catheter of 0.3 $\mathrm{mm}$ outer diameter placed $7 \mathrm{~cm}$ from the anus. The rats were killed 24 hours or seven days after induction of colonic injury and their colons removed. These time intervals represent the acute and chronic responses to TNB.

HBO TREATMENT

The effects of HBO therapy $(100 \%$ oxygen at 2.4 atmosphere absolute (ATA)) were studied in rats in which colitis had been induced and in control rats. The transparent HBO chamber used is identical with that used by Tibbles and Edelsberg $^{1}$ and is large enough to admit an adult person. Both experimental and control rats were placed in this large chamber in the original cages (five rats per cage). Ten rats were exposed in each treatment. Rats were exposed to $\mathrm{HBO}$ for one hour twice at six hour intervals on the day of colitis induction and once daily thereafter until they were killed. All rats were killed by cervical dislocation. The colons were isolated and a $10 \mathrm{~cm}$ segment of the distal colon proximal to the anus was resected, its lumen rinsed with ice cold saline and weighed. Mucosal damage in the $10 \mathrm{~cm}$ distal segment was measured macroscopically by two blinded observers using a stereomicroscope and scored by multiplying the length $(\mathrm{mm})$ and width (mm) of each lesion. For each rat the total score was determined by summing the ulcer scores $\left(\mathrm{mm}^{2}\right)$. Interobserver variation was $7 \%$. Tissue samples were obtained for histological analysis and the remaining mucosa was scraped and processed for determination of eicosanoid generation and myeloperoxidase (MPO) and NOS activities.

DETERMINATION OF NOS ACTIVITY

NOS activity was monitored by measuring the conversion of $\mathrm{L}-\left[{ }^{3} \mathrm{H}\right]$ arginine into citrulline as described by Bush et al. ${ }^{12}$ Mucosal scrapings $(100 \mathrm{mg})$ were homogenised for 30 seconds at $4^{\circ} \mathrm{C}$ with a Polytron (Kinematica $\mathrm{GmbH}$, Kriens-Luzern, Switzerland) in $0.9 \mathrm{ml}$ ice cold $50 \mathrm{mmol} / 1 \mathrm{Tris} / \mathrm{HCl}(\mathrm{pH} 7.4)$ containing 0.1 $\mathrm{mmol} / 1 \mathrm{EDTA}, 0.1 \mathrm{mmol} / 1 \mathrm{EGTA}, 0.5 \mathrm{mmol} / 1$ dithiothreitol, and $1 \mathrm{mmol} / \mathrm{l}$ phenylmethanesulphonyl fluoride. Homogenates were centrifuged at $20000 \mathrm{~g}$ for 60 minutes at $4^{\circ} \mathrm{C}$ and the supernatant was used as the source of NOS. Enzymic reactions were conducted at $37^{\circ} \mathrm{C}$ in $50 \mathrm{mmol} / 1$ Tris/ $\mathrm{HCl}(\mathrm{pH} 7.4)$ containing $100 \mu \mathrm{mol} / 1 \mathrm{~L}$-arginine, $100 \mu \mathrm{mol} / 1 \mathrm{NADPH}$, $2 \mathrm{mmol} / 1 \mathrm{CaCl}_{2}, 0.2-0.4 \mathrm{mg}$ supernatant proteins, and about $200000 \mathrm{dpm} \mathrm{L-[2,3,4,5-}$ ${ }^{3} \mathrm{H}$ ] arginine hydrochloride $(77 \mathrm{Ci} / \mathrm{mmol} ; \mathrm{Am}-$ ersham International, Amersham, Bucks, UK) to a final volume of $100 \mu$ l. Enzyme reactions were also carried out in the absence of $\mathrm{Ca}^{2+}$ and in the presence of EGTA $1 \mathrm{mmol} / 1$. Reactions were terminated by the addition of $2.0 \mathrm{ml}$ ice cold stop buffer $(20 \mathrm{mmol} / \mathrm{l}$ sodium acetate (pH 5.5), $1 \mathrm{mmol} / 1$ L-citrulline, $2 \mathrm{mmol} / 1$ EDTA, and $0.2 \mathrm{mmol} / 1 \mathrm{EGTA})$. Citrulline concentration was determined by applying the samples $(2.0 \mathrm{ml})$ prepared as described above to columns ( $1 \mathrm{~cm}$ diameter) containing $1 \mathrm{ml}$ Dowex AG50W-X8 (sodium form), which had been pre-equilibrated with stop buffer. Columns were eluted with $4 \times 1.0 \mathrm{ml}$ water collected into scintillation vials. Opti-fluor (10 ml; Packard, Meridien, Connecticut, USA) was added to each vial and samples were counted in a Packard Tri-Carb liquid scintillation spectrometer (Amana, Iowa, USA). Citrulline was recovered in the first $4.0 \mathrm{ml}$ of the Dowex column eluate to the extent of $96(2) \%$.

DETERMINATION OF MPO ACTIVITY

Colonic mucosal scrapings (200 mg) were homogenised $(3 \times 30$ seconds $)$ at $4^{\circ} \mathrm{C}$ in a Polytron in $1.0 \mathrm{ml}$ ice cold $0.5 \%$ hexadecyltrimethylammonium bromide in $50 \mathrm{mmol} / \mathrm{l}$ phosphate buffer ( $\mathrm{pH}$ 6.0). The Polytron probe was rinsed twice with $1.0 \mathrm{ml}$ of the buffer and the washings were added to the homogenate. The homogenate was then sonicated for 10 seconds, freeze-thawed three times, and centrifuged for 15 minutes at $40000 \mathrm{~g}$. An aliquot of the supernatant was taken for determination of enzyme activity as described by Bradley et al. ${ }^{13}$

DETERMINATION OF EICOSANOID GENERATION A $150 \mathrm{mg}$ sample of mucosa was placed in a preweighed tube containing $1.0 \mathrm{ml}$ phosphate buffer $(50 \mathrm{mmol} / \mathrm{l}, \mathrm{pH} 7.4)$. The mucosa was minced with scissors and centrifuged in an Eppendorf centrifuge (Hamburg, Germany) for 10 seconds. The pellet was resuspended in $1.0 \mathrm{ml}$ of the above buffer and incubated for 
Table 1 Effect of acetic acid and trinitrobenzenesulphonic acid (TNB) on rat colon

\begin{tabular}{lllll}
\hline & & \multicolumn{2}{l}{ TNB } \\
\cline { 5 - 5 } Treatment & Control & $\begin{array}{l}\text { Acetic acid } \\
\text { (1 day) }\end{array}$ & 1 day & 7 days \\
\hline No of rats & $12-22$ & $12-16$ & $14-21$ & $12-14$ \\
Weight $(\mathrm{g} / 10 \mathrm{~cm})$ & $0.61(0.01)$ & $1.61(0.07)^{\star}$ & $1.80(0.15)^{\star}$ & $3.7(0.4)^{\star}$ \\
MPO $(\mathrm{U} / \mathrm{g})$ & $0.98(0.09)$ & $5.6(0.9)^{\star}$ & $6.9(0.9)^{\star}$ & $4.6(0.9)^{\star}$ \\
NOS $(\mathrm{nmol} / \mathrm{g} / \mathrm{min})+\mathrm{Ca}^{2+}$ & $2.93(0.17)$ & $7.1(1.1)^{\star}$ & $11.8(2.0)^{\star}$ & $4.8(0.3)^{\star}$ \\
NOS $(\mathrm{nmol} / \mathrm{g} / \mathrm{min})-\mathrm{Ca}^{2+}$ & $2.06(0.10)$ & $7.0(1.1)^{\star}$ & $12.0(2.7)^{\star}$ & $4.7(0.3)^{\star}$ \\
$\mathrm{PGE}_{2}(\mathrm{ng} / \mathrm{g})$ & $39.00(1.76)$ & $48.0(2.4)^{\star}$ & $48.0(2.5)^{\star}$ & $48.0(2.3)^{\star}$ \\
$\mathrm{LTB}_{4}(\mathrm{ng} / \mathrm{g})$ & $1.0(0.1)$ & $4.2(1.0)^{\star}$ & $2.5(0.3)^{\star}$ & $1.5(0.1)^{*}$ \\
\hline
\end{tabular}

Results are expressed as mean (SEM)

Colitis was induced with acetic acid or TNB, as described in Materials and Methods. Rats were killed after one or seven days as indicated. The distal $10 \mathrm{~cm}$ long colonic segment was isolated and the mucosa was scraped for determination of eicosanoid generation, and myeloperoxidase (MPO) and nitric oxide synthase (NOS) activities.

Significantly different from control rats, ${ }^{\star} \mathrm{p}<0.05$

$\mathrm{PGE}_{2}$, prostaglandin $\mathrm{E}_{2} ; \mathrm{LTB}_{4}$, leukotriene $\mathrm{B}_{4}$.

one minute in a vortex mixer; $10 \mu \mathrm{g}$ indomethacin was added, and the tubes were centrifuged for 60 seconds. The supernatants were kept at $-20^{\circ} \mathrm{C}$ until radioimmunoassays (RIAs) were performed. The ability of the mucosa to generate leukotriene $\mathrm{B}_{4}\left(\mathrm{LTB}_{4}\right)$ was expressed as $\mathrm{ng} / \mathrm{g}$ of wet tissue weight.

MEASUREMENT OF $\mathrm{LTB}_{4}$ $\mathrm{LTB}_{4}$ immunoreactivity was determined using an RIA kit (TRK 940; Amersham). The assay combines the use of a high specific radioactivity $\mathrm{LTB}_{4}$ tracer, an antiserum specific for $\mathrm{LTB}_{4}$ (cross reactivity 100\%), and a leukotriene standard (range 1.6-200 pg/tube). The specific binding of tracer is $42.5 \%$ and non-specific binding is $2.4 \%$. A $50 \% \mathrm{~B} / \mathrm{B}_{\mathrm{o}}$ displacement is obtained with $15 \mathrm{pg} /$ tube $\mathrm{LTB}_{4}$ and $90 \%$ with $2.2 \mathrm{pg} /$ tube.

MEASUREMENT OF $\mathrm{PGE}_{2}$

$\mathrm{PGE}_{2}$ generation was determined by RIA, as previously described. ${ }^{14}$

MORPHOLOGICAL STUDIES

Sections of colon were obtained from the same areas of the large intestine from four representative animals in each of the treatment groups during autopsy. They were fixed in phosphate buffered formaldehyde, embedded in paraffin, and routine $5 \mu \mathrm{m}$ sections were prepared. Tissues were routinely stained with haematoxylin and eosin and were evaluated by light microscopy by a pathologist unaware of the experiments being performed.

Table 2 Effect of hyperbaric oxygen (HBO) on colonic weight, eicosanoid generation, and myeloperoxidase (MPO) and nitric oxide synthase (NOS) activities

\begin{tabular}{llll}
\hline & & \multicolumn{3}{l}{$H B O$} \\
\cline { 3 - 4 } Treatment & Control & 1 day & 7 days \\
\hline No of rats & $12-22$ & $8-10$ & 6 \\
Weight $(\mathrm{g} / 10 \mathrm{~cm})$ & $0.61(0.01)$ & $0.58(0.02)$ & $0.60(0.03)$ \\
MPO $(\mathrm{U} / \mathrm{g})$ & $0.98(0.09)$ & $0.76(0.13)$ & $1.60(0.20)$ \\
NOS $(\mathrm{nmol} / \mathrm{g} / \mathrm{min})+\mathrm{Ca}^{2+}$ & $2.93(0.17)$ & $3.30(0.18)$ & $1.10(0.07)^{\star}$ \\
NOS $(\mathrm{nmol} / \mathrm{g} / \mathrm{min})-\mathrm{Ca}^{2+}$ & $2.06(0.10)$ & $2.90(0.10)$ & $0.32(0.09)^{\star}$ \\
$\mathrm{PGE}_{2}(\mathrm{ng} / \mathrm{g})$ & $39.00(1.76)$ & $26.00(1.48)^{\star}$ & $33.70(4.30)$ \\
$\mathrm{LTB}_{4}(\mathrm{ng} / \mathrm{g})$ & $1.00(0.10)$ & $\mathrm{NT}$ & $1.8(0.25)$
\end{tabular}

Results are expressed as mean (SEM).

Rats were treated with HBO as described in Materials and Methods. Rats were killed after one or seven days as indicated. The distal $10 \mathrm{~cm}$ long colonic segment was isolated and the mucosa was scraped for determination of eicosanoid generation, and MPO and NOS activities.

Significantly different from control, untreated rats, ${ }^{\star} \mathrm{p}<0.05$.

$\mathrm{PGE}_{2}$, prostaglandin $\mathrm{E}_{2} ; \mathrm{LTB}_{4}$, leukotriene $\mathrm{B}_{4} ; \mathrm{NT}$, not tested.
STATISTICAL ANALYSIS

Data are expressed as mean (SEM). Statistical analysis for significant differences was performed in all instances by Student's $t$ test for unpaired data and the non-parametric MannWhitney U test.

\section{Results}

EFFECT OF ACETIC ACID AND TNB ON THE RAT COLON

The wet weight of the $10 \mathrm{~cm}$ long distal colonic segment, mucosal eicosanoid generation, and MPO and NOS activities in rats treated with acetic acid or TNB but not exposed to HBO were significantly higher than in control untreated rats (table 1).

EFFECT OF HBO TREATMENT ON THE COLON OF CONTROL RATS

HBO treatment did not affect body weight. The body weight of control rats not exposed to $\mathrm{HBO}$ was 200 (5) g ( $=12), 207$ (3) g ( $\mathrm{n}=$ $10)$, and $249(12) \mathrm{g}(\mathrm{n}=6)$ on day 0 and after one and seven days. In rats exposed to HBO the body weights were $202(5) \mathrm{g}(\mathrm{n}=10), 210$ (4) $\mathrm{g}(\mathrm{n}=10)$, and 253.0 (4.5) g $(\mathrm{n}=8)$ respectively. In control rats exposed to $\mathrm{HBO}$ for one or seven days, the wet weight of the 10 $\mathrm{cm}$ colonic segment and MPO activity were similar to those in untreated rats. After seven days of HBO treatment, colonic NOS activity was significantly decreased. Colonic $\mathrm{PGE}_{2}$ generation was significantly decreased after the first day of HBO treatment, whereas at seven days, both $\mathrm{PGE}_{2}$ and $\mathrm{LTB}_{4}$ generation were similar to that in control untreated rats (table 2).

Histological examination of sections of the large intestine of six normal rats treated for 24 hours with $\mathrm{HBO}$ showed normal colonic mucosa in all of them. After seven days of $\mathrm{HBO}$ treatment the mucosa was normal in three of the six rats examined, but in the other three there were small superficial ulcerations with no reactive infiltrate.

\section{EFFECT OF HBO ON ACETIC ACID INDUCED} COLITIS

At 24 hours after administration of acetic acid the colon was haemorrhagic and inflamed. Exposure to HBO significantly reduced by half the extent of the acetic acid induced lesion area. In $\mathrm{HBO}$ treated rats the wet weight was also significantly decreased compared with the wet weight of the colonic segment in rats treated with acetic acid only (fig 1 ).

Mucosal MPO activity in control and acetic acid treated rats was $1.26(0.14)(\mathrm{n}=12)$ and $5.60(0.85)(\mathrm{n}=12)$ units/g respectively. In rats treated with acetic acid and HBO, MPO activity was significantly reduced to $3.2(0.3)$ units/g, almost half of its activity in rats treated with acetic acid only. In acetic acid treated rats, both $\mathrm{PGE}_{2}$ and $\mathrm{LTB}_{4}$ generation was increased compared with that in normal untreated rats (tables 1 and 2). Exposure of acetic acid treated rats to $\mathrm{HBO}$ resulted in an almost $50 \%$ decrease in $\mathrm{PGE}_{2}$ and $\mathrm{LTB}_{4}$ generation (table 3). In acetic acid treated rats, colonic mucosal NOS activity-7.10 (1.05) $(\mathrm{n}=12) \mathrm{nmol} / \mathrm{g} /$ 


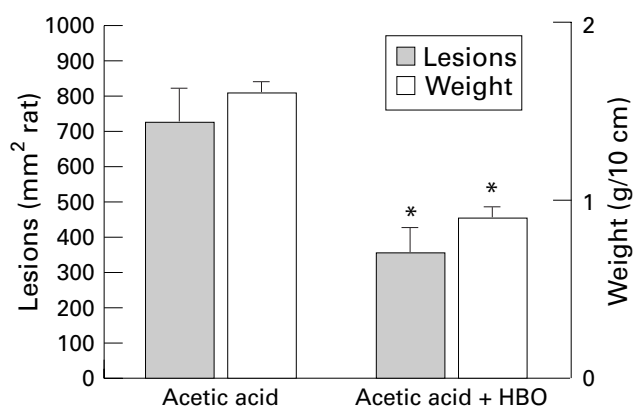

Figure 1 Effect of hyperbaric oxygen (HBO) on colonic lesion area and weight in acetic acid treated rats. Colitis was induced by injection of $2.0 \mathrm{ml} 5 \%$ acetic acid into the proximal colon. One group of rats was exposed twice for one hour to $\mathrm{HBO}(100 \%$ oxygen at $2.4 \mathrm{ATA})$. Rats were killed after 24 hours. The colon was isolated and weighed and the lesion area measured. Results are mean (SEM) for 8-16 rats in each group. ${ }^{\star}$ Significantly different from acetic acid only $(p<0.05)$.

min, which is more than twofold higher than in control rats - was significantly reduced in acetic acid treated rats exposed to $\mathrm{HBO}$ (table 3).

Histological examination showed that in all rats treated with acetic acid there were widespread mucosal ulcerations with significant oedema of the submucosa, accompanied by inflammatory cell infiltrate involving all layers of the bowel wall. In two of seven rats treated with acetic acid and $\mathrm{HBO}$ there were only minute superficial ulcerations involving not more than one third of the mucosal width and accompanied by minimal inflammatory cell infiltrate (fig 2A). In the other five rats treated with acetic acid and HBO the histological findings were similar to those in rats treated with acetic acid only. In these rats there were wide mucosal ulcerations involving the whole mucosal width with significant inflammatory cell infiltrate (fig 2B).

EFFECT OF HBO ON TNB INDUCED COLITIS Intracolonic administration of $\mathrm{TNB} /$ ethanol resulted in extensive haemorrhagic and ulcerative damage to the colon. By 24 hours the lesion area was $1004(81) \mathrm{mm}^{2} /$ rat $(\mathrm{n}=14)$. Seven days after damage induction, the lesion area was 1053 (182) $\mathrm{mm}^{2}$. Exposure to HBO induced a significant decrease of $55 \%$ in the lesion area observed 24 hours after damage

Table 3 Effect of hyperbaric oxygen (HBO) on colonic mucosal eicosanoid generation, and myeloperoxidase (MPO) and nitric oxide synthase (NOS) activities in acetic acid treated rats

\begin{tabular}{lll}
\hline Treatment & Acetic acid & $\begin{array}{l}\text { Acetic acid } \\
+\mathrm{HBO}\end{array}$ \\
\hline No of rats & $12-16$ & $8-10$ \\
$\mathrm{MPO}(\mathrm{U} / \mathrm{g})$ & $5.6(0.9)$ & $3.2(0.3)^{\star}$ \\
$\mathrm{NOS}(\mathrm{nmol} / \mathrm{g} / \mathrm{min})+\mathrm{Ca}^{2+}$ & $7.1(1.1)$ & $4.0(0.4)^{\star}$ \\
NOS $(\mathrm{nmol} / \mathrm{g} / \mathrm{min})-\mathrm{Ca}^{2+}$ & $7.0(1.1)$ & $3.3(0.3)^{\star}$ \\
$\mathrm{PGE}_{2}(\mathrm{ng} / \mathrm{g})$ & $48.0(2.4)$ & $26.8(3.1)^{\star}$ \\
$\mathrm{LTB}_{4}(\mathrm{ng} / \mathrm{g})$ & $4.2(1.0)$ & $2.2(0.4)^{\star}$ \\
\hline
\end{tabular}

Results are expressed as mean (SEM).

Colitis was induced with acetic acid and followed with $\mathrm{HBO}$ treatment as described in Materials and Methods. Rats were killed after 24 hours. The distal $10 \mathrm{~cm}$ long colonic segment was isolated and the mucosa was scraped for determination of eicosanoid generation, and MPO and NOS activities. Significantly different from acetic acid only, ${ }^{\star} \mathrm{p}<0.05$ $\mathrm{PGE}_{2}$, prostaglandin $\mathrm{E}_{2} ; \mathrm{LTB}_{4}$, leukotriene $\mathrm{B}_{4}$.

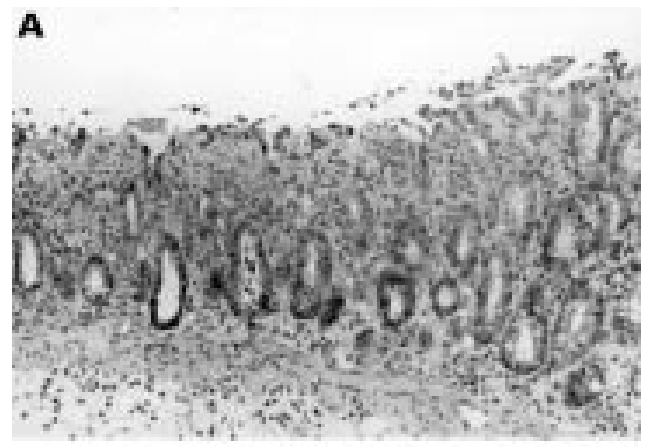

B

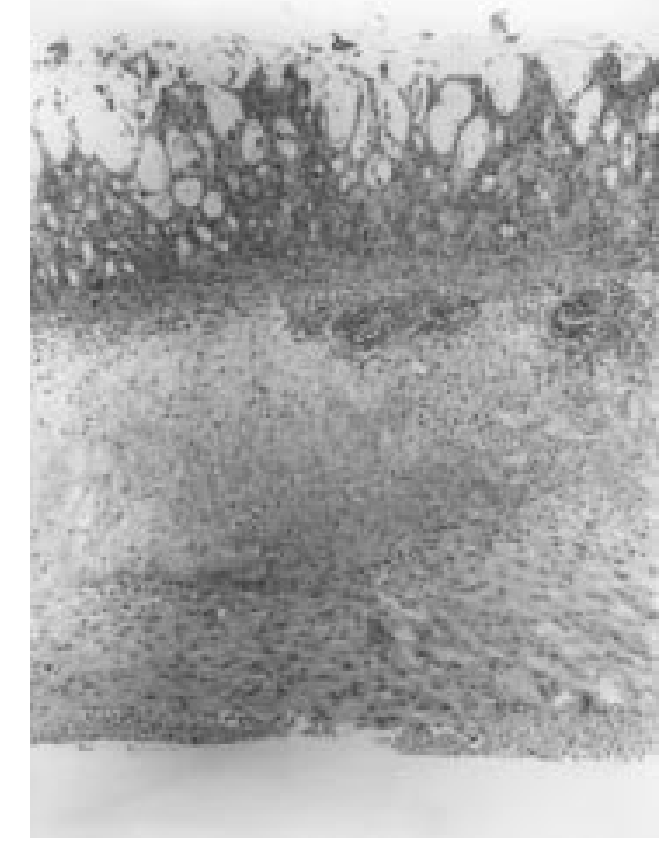

Figure 2 Histological section of the colon isolated from rats treated with acetic acid and hyperbaric oxygen. (A) Small mucosal ulcerations can be seen with an acute mild inflammatory cell infiltrate involving the upper third to one half of the mucosal thickness. Haematoxylin and eosin staining; original magnification $\times 187$. (B) Wide mucosal ulceration can be seen with an extensive inflammatory cell infiltrate involving all layers of the intestinal wall.

Haematoxylin and eosin staining; original magnification $\times$ 71.

induction. Seven days after induction of damage the decrease in the extent of the damage averaged $63 \%$ in $\mathrm{HBO}$ treated rats. The amelioration of the severity of the inflammatory response in $\mathrm{HBO}$ treated rats was also reflected by the difference in the wet weight of the $10 \mathrm{~cm}$ long distal colonic segment (fig 3).

MPO activity in rats treated with TNB and $\mathrm{HBO}$ was significantly lower than in rats treated with TNB only. One and seven days after TNB treatment, colonic NOS activity was significantly increased compared with that in control rats. In those treated with TNB and $\mathrm{HBO}$, colonic NOS activity was significantly lower than in TNB treated rats one and seven days after treatment (table 4). $\mathrm{PGE}_{2}$ generation was significantly reduced in rats treated with TNB and HBO, whereas mucosal $\mathrm{LTB}_{4}$ generation was not significantly affected by HBO treatment (table 4). 

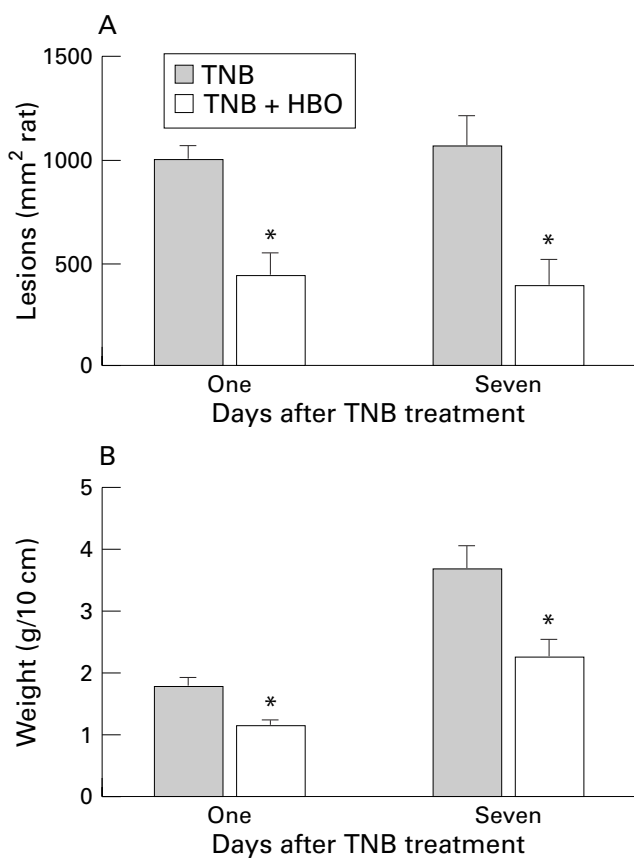

Figure 3 Effect of hyperbaric oxygen (HBO) on colonic lesion area $(A)$ and weight $(B)$ in rats treated with trinitrobenzenesulphonic acid (TNB). Colitis was induced by intracolonic administration of TNB. Rats were treated for one hour with $\mathrm{HBO}(100 \%$ oxygen at $2.4 \mathrm{ATA})$ twice daily in the first 24 hours and once daily thereafter. They were killed after one or seven days. The distal $10 \mathrm{~cm}$ of the colon was isolated and weighed and the lesion area measured. Results are mean (SEM) for 8-12 rats in each group. *Significantly different from TNB alone $(p<0.05)$.

Histological examination of mucosa taken 24 hours after treatment with TNB showed widespread haemorrhagic ulcerations of the whole mucosal width with significant inflammatory cell infiltrate and submucosal oedema. In three of eight rats treated with TNB and HBO, after 24 hours there were only a few superficial mucosal ulcerations involving one third of the mucosa with slight oedema, whereas the rest of the segment was normal (fig $4 \mathrm{~A}$ ). In the other five rats treated with TNB and HBO, after 24 hours there were widespread ulcerations with inflammatory cell infiltrate and submucosal oedema (fig 4B). Seven days after treatment with TNB and HBO, in eight of ten rats, the histological findings were similar to those in rats treated with TNB only. There was widespread ulceration with granulation of tissue and inflammatory cell infiltrate.

Table 4 Effect of hyperbaric oxygen (HBO) on colonic mucosal eicosanoid generation, and myeloperoxidase (MPO) and nitric oxide synthase (NOS) activities in trinitrobenzenesulphonic acid (TNB) treated rats

\begin{tabular}{|c|c|c|c|c|}
\hline \multirow[b]{2}{*}{ Treatment } & \multicolumn{2}{|l|}{$T N B$} & \multicolumn{2}{|c|}{$T N B+H B O$} \\
\hline & 1 day & 7 days & 1 day & 7 days \\
\hline No of rats & $14-21$ & $12-14$ & 8 & 10 \\
\hline $\mathrm{MPO}(\mathrm{U} / \mathrm{g})$ & $6.9(0.9)$ & $4.6(0.9)$ & $4.0(0.7)$ & $1.4(0.2)^{\star}$ \\
\hline $\mathrm{NOS}(\mathrm{nmol} / \mathrm{g} / \mathrm{min})+\mathrm{Ca}^{2+}$ & $11.8(2.0)$ & $4.8(0.3)$ & $4.2(0.1)^{\star}$ & $2.7(0.3)^{\star}$ \\
\hline $\mathrm{NOS}(\mathrm{nmol} / \mathrm{g} / \mathrm{min})-\mathrm{Ca}^{2+}$ & $12.0(2.7)$ & $4.7(0.3)$ & $3.1(0.3)^{\star}$ & $2.4(0.2)^{\star}$ \\
\hline $\mathrm{PGE}_{2}(\mathrm{ng} / \mathrm{g})$ & $48.0(2.5)$ & $48.0(2.3)$ & $21.8(2.7)^{\star}$ & $28.9(2.4)^{\star}$ \\
\hline $\mathrm{LTB}_{4}(\mathrm{ng} / \mathrm{g})$ & $2.5(0.3)$ & $1.5(0.1)$ & $1.8(0.3)$ & $1.4(0.2)$ \\
\hline
\end{tabular}

Results are expressed as mean (SEM).

Colitis was induced with TNB and rats were exposed to $\mathrm{HBO}$ as described in Materials and Methods. Rats were killed after one or seven days of treatment as indicated. The distal $10 \mathrm{~cm}$ long colonic segment was isolated and the mucosa was scraped for determination of eicosanoid generation, and MPO and NOS activities.

Significantly different from TNB only, ${ }^{\star} \mathrm{p}<0.05$.

$\mathrm{PGE}_{2}$, prostaglandin $\mathrm{E}_{2} ; \mathrm{LTB}_{4}$, leukotriene $\mathrm{B}_{4}$.
A

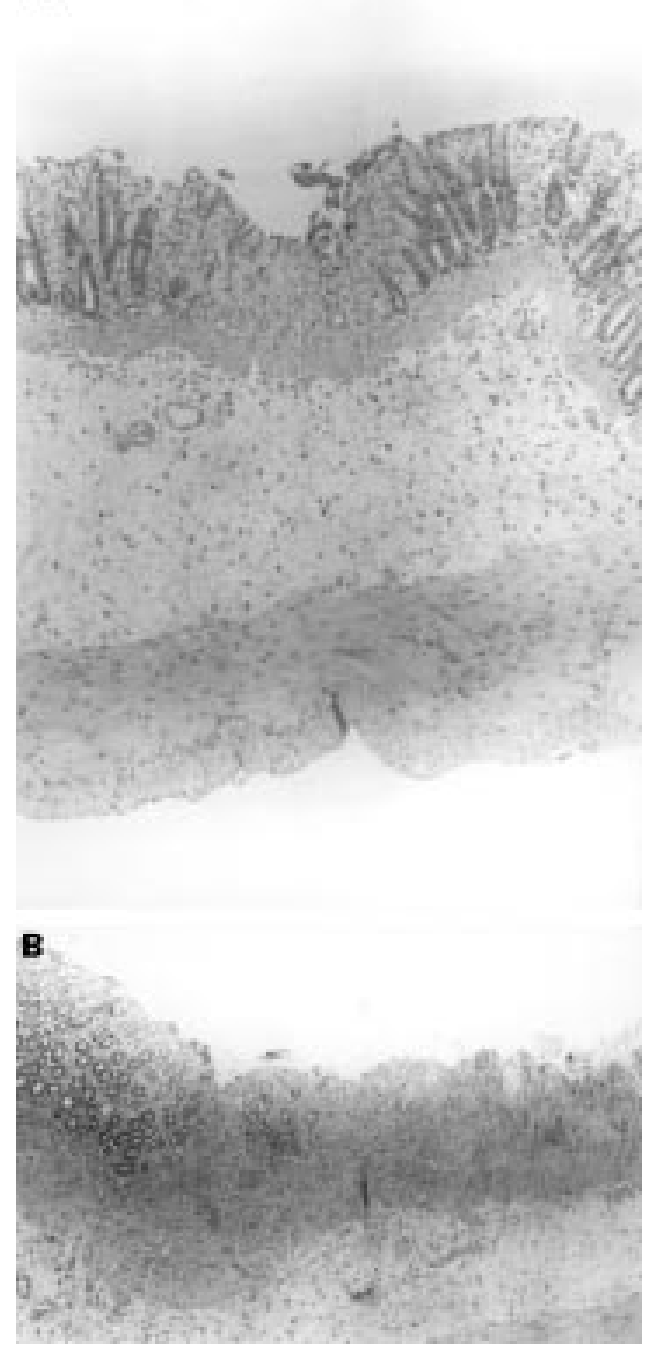

Figure 4 Histological section of the colon isolated 24 hours after intracolonic treatment with trinitrobenzenesulphonic acid and exposure to hyperbaric oxygen. (A) A small superficial ulcer can be seen involving only the mucosa and accompanied by a very mild acute inflammatory cell infiltrate. Haematoxylin and eosin staining; original magnification $\times 71$. (B) Wide and extensive mucosal ulcers are evident. Haematoxylin and eosin staining; original magnification $\times 71$.

In only two rats treated with TNB and HBO was the mucosa normal after seven days.

\section{Discussion}

In the present study the possible application of $\mathrm{HBO}$ as a novel therapeutic approach for amelioration of the inflammatory response in patients with IBD was found to be very effective in decreasing tissue damage in two models of experimental colitis. In addition, decreased $\mathrm{PGE}_{2}$ generation and NOS activity were found to be induced by hyperbaric oxygenation, suggesting that they may be involved in the therapeutic effects in experimental colitis and patients with IBD.

$\mathrm{HBO}$ has been described as a therapy in search of diseases. ${ }^{15}$ Although many of its clinical uses are controversial, its application has been evaluated in the search for treatments for pathological conditions, especially those of unknown aetiology. The clinical use of HBO 
therapy has been reviewed recently. ${ }^{1} \mathrm{HBO}$, which is $100 \%$ oxygen at two to three times the atmospheric pressure at sea level, may result in increased $\mathrm{PaO}_{2}$ in excess of $2000 \mathrm{~mm} \mathrm{Hg}$ and tissue $\mathrm{PO}_{2}$ of almost $400 \mathrm{~mm} \mathrm{Hg}$. Such excessive $\mathrm{PO}_{2}$ may have a number of beneficial biochemical, cellular, and physiological effects, among which are alleviation of tissue hypoxia and restoration of tissue defence against bacterial infection. $\mathrm{HBO}$ is bactericidal for certain anaerobic pathogens and suppresses clostridial production of $\alpha$-toxin. It promotes wound healing and mitigates post-ischaemicreperfusion injury, probably by suppressing neutrophil adherence and production of free radicals.

HBO treatment is the definitive treatment (often life-saving) for decompression sickness after underwater diving accidents, arterial gas embolism, or carbon monoxide poisoning. $\mathrm{HBO}$ has also been used with varying degrees of success to promote healing of tissues damaged by radiation, infection, and mechanical or thermal trauma. In addition, $\mathrm{HBO}$ is a useful adjunct in the management of problem wounds complicating diabetes mellitus and vascular diseases. When used with pressures of $3 \mathrm{~atm}$ or less in sessions of 120 minutes or less, $\mathrm{HBO}$ treatment is safe. If these limits are exceeded, it may cause generalised seizures and temporary impairment of inner ear function.

In view of the various positive therapeutic effects of $\mathrm{HBO}$, it was also used for patients suffering from severe perianal Crohn's disease. ${ }^{45}$ In the present study we tried to substantiate the positive anti-inflammatory effects of $\mathrm{HBO}$ in models of experimental colitis and to elucidate its effects on the inflammatory mediators involved in the pathogenesis of experimental colitis.

Models of experimental colitis differ fundamentally from human IBD. However, irrespective of their cause, in the experimental model the inflammatory response resembles, in many aspects, the sequence of events in IBD. HBO was found in the present study to significantly decrease the extent of tissue damage in both acetic acid- and TNB-induced colitis. A significant effect was already observed 24 hours after induction of the injury and, in the TNB model, also after seven days. The decrease in tissue damage was apparent macroscopically by measuring the lesion area and also the colonic wet weight. Wet weight has been found to be a very accurate, sensitive, and reliable marker of tissue damage in models of experimental colitis. ${ }^{16}$ The decrease in the extent of tissue injury was less pronounced histologically. In both the TNB and acetic acid models, at 24 hours, an effect of $\mathrm{HBO}$ on the extent of tissue injury was apparent on histological examination only in one quarter to one third of the treated animals. At seven days, in the TNB model, a beneficial effect of HBO was observed histologically in only $20 \%$ of the animals. A lack of correlation between the macroscopical and histological effects of pharmacological manipulation of colonic inflammation in models of experimental colitis has been reported previously. In rat models of coli- tis induced by iodoacetamide, ${ }^{17}$ acetic acid or TNB,${ }^{9}$ the morphological effects of L-NAME and nitroxide were also less remarkable than their effects on the macroscopic appearance of the mucosa. It therefore seems that, in models of colonic inflammation, irrespective of the therapeutic modality, HBO included, the beneficial histological effect is less pronounced and lags after the macroscopic effects. As in the present study, most time courses in models of experimental colitis have apparently been too short to allow a significant histological effect.

A possible mechanism to explain the effect of $\mathrm{HBO}$ on the extent of tissue injury in these models of experimental colitis is an effect on the inflammatory mediators involved in the pathogenesis of tissue inflammation. The effects of HBO treatment on mucosal eicosanoid generation and MPO and NOS activities were therefore evaluated. MPO activity generated by granulocytes is stimulated both in acetic acid and TNB colitis. ${ }^{9}$ In the present study MPO activity was found to be significantly decreased in the acetic acid model and in TNB induced colitis after seven days of exposure to HBO. The decrease in the extent of inflammation is accompanied, as in the other pharmacological manipulations, by a decrease in $\mathrm{MPO}$ activity.

Amelioration of tissue injury in both models was also accompanied by a significant decrease in mucosal NOS activity. Most of the colonic NOS activity in all treatment groups at the various time intervals was independent of calcium and thus represents the inducible form. In both models of colitis, NO generation by stimulated NOS activity has been shown previously to be enhanced. ${ }^{7}$ The enhanced NO generation may make an important contribution to the pathogenesis of the damage, as indicated by the impressive amelioration of tissue damage induced by specific inhibition of NOS activity in this ${ }^{9}$ and other ${ }^{17}$ models of experimental colitis.

The decrease in mucosal NOS activity may be secondary to the decrease in the number of inflammatory cells and/or the decrease in their activity after $\mathrm{HBO}$ treatment. Alternatively, the decrease in mucosal NOS activity may be a primary event whereby HBO exerts its beneficial effects. This possibility is supported by the observation in the present study that seven days exposure of control untreated rats to $\mathrm{HBO}$ also resulted in significant suppression of this enzyme activity, whereas MPO activity was not affected. No effect of one day of $\mathrm{HBO}$ treatment of control rats on NOS activity was observed, probably because NOS activity is not induced in control rats and a short HBO treatment is not powerful enough.

It has been shown previously that, in models of experimental colitis, mucosal $\mathrm{PGE}_{2}$ and $\mathrm{LTB}_{4}$ generation are enhanced, and it has been suggested that they may contribute to the pathogenesis of tissue damage. Amelioration of the extent of tissue injury by $\mathrm{HBO}$ treatment is accompanied by significant decreases in $\mathrm{PGE}_{2}$ generation in both models and, in the acetic acid model, also by a significant decrease in mucosal $\mathrm{LTB}_{4}$ generation. The involvement 
and role of mucosal eicosanoids differ with respect to the specific injurious agent. A lack of correlation between histological improvement and mucosal $\mathrm{LTB}_{4}$ generation has also been reported for iodoacetamide induced colitis. ${ }^{17} \mathrm{It}$ is therefore unlikely that a specific effect of $\mathrm{HBO}$ on $\mathrm{LTB}_{4}$ generation contributes to its effects in TNB induced colitis, whereas in the acetic acid model, this may be one of the mechanisms contributing to its effects. In the colon, $\mathrm{PGE}_{2}$ is regarded as one of the pro-inflammatory mediators; its role in other organs ${ }^{18}$ and its decrease after $\mathrm{HBO}$ treatment suggest that it may contribute to the antiinflammatory effects of HBO. Similarly, inhibition of $\mathrm{PGE}_{2}$ generation by COX-2 inhibitors may be of value in the treatment of colonic inflammation.

Another possible mechanism to explain the beneficial effect of $\mathrm{HBO}$ may involve the superficial mucosal damage observed in control rats treated for seven days with HBO. In the upper gut, superficial mucosal injury induced by mild irritants has been shown to protect the mucosa against subsequent injury, a process termed adaptive cytoprotection. ${ }^{19}$ Similar mechanisms may exist in the colon and may explain how $\mathrm{HBO}$ treatment that causes superficial ulceration protects against more severe injury.

In conclusion, in the present study, HBO treatment was shown to modulate the extent of tissue injury in two models of experimental colitis. This effect is accompanied by a significant decrease in NOS activity, which may be among the mechanisms to explain the benefits of HBO treatment in experimental colitis and maybe even in human IBD.

1 Tibbles PM, Edelsberg JS. Hyperbaric oxygen therapy. $N$ Engl f Med 1996;334:1642-8.

2 Zamboni WA, Roth AC, Russell RC, et al. Morphologic analysis of the microcirculation during reperfuson of ischemic skeletal muscle and the effect of hyperbaric oxygen. Plast Reconstr Surg 1993;91:1110-23.

3 Yamada T, Taguchi T, Hirata Y, et al. The protective effect of hyperbaric oxygenation on the small intestine in ischemia reperfusion injury. F Pediatr Surg 1995;30:786-90.

4 Lavy A, Weisz G, Adir Y, et al. Hyperbaric oxygen for perianal Crohn's disease. F Clin Gastroenterol 1994;19:202-5.

5 Colombel JF, Mathieu D, Bonault JM, et al. Hyperbaric oxygenation in severe perianal Crohn's disease. Dis Colon Rectum 1995;38:609-14.

6 Eliakim R, Rachmilewitz D. Potential mediators in inflammatory bowel disease. Gastroenterology International 1992;5: $48-56$.

7 Rachmilewitz D, Stamler JS, Bachwich D, et al. Enhanced colonic nitric oxide generation and nitric oxide synthase activity in ulcerative colitis and Crohn's disease. Gut 1995; 36:718-23.

8 Rachmilewitz D, Stamler JS, Karmeli F, et al. Peroxynitriteinduced rat colitis: a new model of colonic inflammation. Gastroenterology 1993;105:1681-8.

9 Rachmilewitz D, Karmeli F, Okon E, et al. Experimental colitis is ameliorated by inhibition of nitric oxide synthase activity. Gut 1995;37:247-55.

10 Karmeli F, Eliakim R, Okon E, et al. A stable nitroxide radical effectively decreases mucosal damage in experimental colitis. Gut 1995;37:386-93.

11 Kurata S, Yamashita U, Nakajima H. Hyperbaric oxygenation reduces the cytostatic activity and transcription of nitric oxide synthetase gene of mouse peritoneal macrophages. Biochim Biophys Acta 1995;1263:35-8.

12 Bush PA, Gonzalez NE, Griscavage JM, et al. Nitric oxide synthase from cerebellum catalyzes the formation of equimolar quantities of nitric oxide and citrulline from L-arginine. Biochem Biophys Res Commun 1992;185:960-6.

13 Bradley PP, Prichat DA, Christensen RD, et al. Measurement of cutaneous inflammation; estimation of neutrophil content with an enzyme marker. $\mathcal{F}$ Invest Dermatol 1982;78: 206-9.

14 Sharon P, Ligumsky M, Rachmilewitz D, et al. Role of prostaglandins in ulcerative colitis: enhanced production during active disease and inhibition by sulphasalazine. Gastroenterology 1978;65:638-40.

15 Gabb G, Robin ED. Hyperbaric oxygen therapy in search of diseases. Chest 1987;92:1074-82.

16 Rachmilewitz D, Simon PL, Schwartz LW, et al. Inflammatory mediators of experimental colitis in rats. Gastroenterology 1989;97:326-37.

17 Rachmilewitz D, Karmeli F, Okon E. Sulphydryl blockerinduced rat colonic inflammation is ameliorated by inhibition of nitric oxide synthase. Gastroenterology 1995;109:98106.

18 Ferreira SH, Moncada S, Vane JR. Prostaglandins and signs and symptoms of inflammation. In: Robinson HJ, Vane JR, eds. Prostaglandin synthetase inhibitors. New York: Raven Press, 1974:175-87.

19 Robert A, Nezamis JE, Lancaster C, et al. Cytoprotection by prostaglandins in rats. Prevention of gastric necrosis produced by alcohol, $\mathrm{HCl}, \mathrm{NaOH}$ and thermal injury. Gastroenterology 1979;77:433-43. 